\title{
The Influence of Stressful Life Events of College Students on Subjective Well-Being: The Mediation Effect of the Operational Effectiveness
}

\author{
Linping Hou*, Yaozhong Liu \\ Jinan University, Guangzhou, China \\ Email: "sudieer@126.com
}

Received 11 May 2016; accepted 12 June 2016; published 15 June 2016

Copyright (C) 2016 by authors and Scientific Research Publishing Inc.

This work is licensed under the Creative Commons Attribution International License (CC BY). http://creativecommons.org/licenses/by/4.0/

(c) (i) Open Access

\begin{abstract}
In this study, we adopted three questionnaires to collect the data of stressful life events, operational effectiveness and subjective well-being of college students. Using SPSS 16.0 and AMOS software, we analysed the relation between stressful life events, operational effectiveness and subjective well-being. It turned out that a) subjective well-being decreases when stressful life events increases, subjective well-being increases when operational effectiveness increases; b) there are four paths through which stressful life events influences subjective well-being: stressful life events have a direct negative effect on subjective well-being; stressful life events affect subjective wellbeing through confidence; stressful life events affect subjective well-being through cognitive level and degree of confidence; stressful life events affect subjective well-being through confidence and competence.
\end{abstract}

\section{Keywords}

Stressful Life Events, Operational Effectiveness, Subjective Well-Being, College Students, Mediation Effect

\section{Introduction}

\subsection{Stressful Life Events}

College students are a special group, they are in a critical period and transitional period before entering society,

*Corresponding author.

How to cite this paper: Hou, L.P. and Liu, Y.Z. (2016) The Influence of Stressful Life Events of College Students on Subjective Well-Being: The Mediation Effect of the Operational Effectiveness. Open Journal of Social Sciences, 4, 70-76.

http://dx.doi.org/10.4236/jss.2016.46008 
in this stage they face the dual pressure of school and working. As the period of the stressful life events happen more often, it is also a huge challenge for their well-being. College students of stressful life events mainly come from relationships, learning pressure, blamed by the teacher, friends and relatives, friends and relatives or property losses, health problems, and the new environment adaptation and so on. On the other hand, because of the particularity of college students' ages, although the age has reach that level, psychological and social adaptation are not, and therefore in the phase of between adults and minors. At adult age, they will face a series of stressful life events, but because of socialization is not enough, it's hard for them to cope with psychological stressful life events; the low level of operational effectiveness also has affection on the overall subjective wellbeing.

Studies have pointed out that there were significant positive correlation between the stressful life events and individual alcohol [1] (Fei Xia, Baojuan Ye, 2014), drugs, [2] (Qiang Yang, Baojuan Ye, 2014) use and suicide rate [3] (Hao Li, Wei Zhang, 2011). At the same time, some studies have shown that stressful life events have significant effects on adolescent subjective well-being [4] (Qiaoqiao Fu, Baojuan Ye, zhong-lin Wen, 2012). The stressful life events refer to the individual life of all kinds of negative events, are able to different degree effects on the individual's psychological and physiological health. Due to the particularity of college students' physical and psychological, stressful life events may have the impact of subjective well-being.

Based on previous studies, this research puts forward assumption that stressful life events influence the subjective well-being of college students negatively.

\subsection{Operational Effectiveness and Subjective Well-Being}

Studies have shown that the higher the operational effectiveness of the individual, the better his ther academic achievement [5] (Jianping Wang, Dongping Li, Wei Zhang, 2010). On this basis, this study puts forward hypothesis: the higher operational effectiveness, the more positive qualities individual has, facing with a stressful life events in their lives, the more effectively processing, and the greater individual's subjective well-being. According to pressure vulnerability model, reaching a certain level of the risk, the protective factors will weaken its ability to fight against risk [5] (Jianping Wang, 2010), which means, in a less stressful life events, positive personal qualities adapt well, subjective well-being is higher, however, more and more serious of stressful life events, their resilience reduces rapidly, individual subjective well-being abate [4] (QiaoqiaoFu, zhong-lin Wen, 2012). Li Dongping (2012) “a drop in the bucket” model provides a support for this hypothesis, the model considering the relationship between the resources of the risk factors and social adaptation has a regulation, risk factors will weaken the beneficial effects of resource factors, in particular, when the risk is low, resources have beneficial influence factors on the social adaptation, risks goes high, the resource of favorable factors significantly reduced. Besides, there are a lot of empirical studies also provided evidence to support this hypothesis, for example, in a more stressful life events or more serious cases, resilience, gratitude, positive traits, such as emotional intelligence ability against risk reduce significantly [4] (Fu Qiaoqiao et al., 2012). College students are during before entering society transition and the critical period, according to the stress vulnerability model, in the face of more frequent or severe stressful life events, their ability to cope with effectiveness against the risk of stressful life events may have fallen, at this point, promote the role the operational effectiveness of subjective well-being of students reduced; Less stressful life events occur, the operational effectiveness of college students may also can fight against the negative impact of stressful life events; At this point, the promoting effect of operational effectiveness to strengthen college students' subjective well-being becomes stronger. But recent studies have come to the conclusion that to the contrary, although the risk factors and the relationship between social adaptation and resource factor has a regulation to reach consensus, but not risk factors for resources factors caused the beneficial effects of inhibition ("resource conservation" model). In other words, when the risk is higher, or lower, resource factors have a positive impact on social adaptation, this view also confirmed in the empirical research on [4] (BaojuanYe, QiangYang, zhujing Hu, 2013). Based on this view, whether in the environment of the stressful life events is higher, or in a less stressful life events in the environment, the operational effectiveness of college students may still can deal with stressful life events about risk, the operational effectiveness of subjective well-being of promoting effect is still strong. In other words, those college students whose operational effectiveness is higher are more happier than those whose lower. To sum up, as both model based on resource protection and pressure vulnerability model pointed out that operational effectiveness has effect on college students' subjective well-being. This study hypothesized, operational effectiveness play role on college 
students' subjective well-being.

\subsection{The Mediator Effect of Operational Effectiveness}

Operational effectiveness originated in the research of self-efficacy. Self-efficacy is a core concept that Bandura (1977) proposed in his social learning theory. Self-efficacy refers to the judgment of subject whether oneself can perform a particular task ability, and the main body feeling: is faith in the ability of self. In recent years, selfefficacy is widely used in the interpretation of the main body behavior; Studies have also applied to the individual life experience, traumatic experience, etc., and the specific areas of self-efficacy to become operational effectiveness.

Research has shown that stressful life events negatively predict adolescents' subjective well-being [4] (Qiaoqiao Fu, Baojuan Ye, zhong-lin Wen, 2012). In this study where college students as participants repeated the experiment, and confirmed that stressful life events also negatively predict the subjective well-being of college students. Although the stressful life events has a direct effect on the individual subjective well-being, but what is the mechanism? Ever less study of stressful life events on the mediation mechanism of college students' subjective well-being. Researchers recently pointed out, merely explore the direct link between variables is not enough, only the introduction of mediation variables can reveal the stressful life events is "how to" work on college students' subjective well-being of [4] [6] (Baojuan Ye, Xiaoyu Hu, Qiang Yang, Zhujing Hu, 2014). On the basis of literature review, this study thought operational effectiveness may be a worth considering mediation variable. Operational effectiveness (coping efficacy) refers to the individual demand for oneself can handle stressful situation and deal with the situation aroused the general belief (Sandler, Tein, Mehta, Wolchik, \& Ayers, 2000). Similar to the emotional evaluation-"excited" theory that the individual can produce certain emotions, measure and evaluation is the key to the individual to spur, stressful life events can significantly affect college students' subjective well-being, the key is that college students is how to deal with stressful life events that had happened. On this basis, this study puts forward assumption: operational effectiveness is stressful life events the mediating role of the college students' subjective well-being.

In sum, this study proposed a mediation model. The purpose of this study has two: 1) target college students to investigate the relationship between the stressful life events and subjective well-being. 2) investigate if there is operational effectiveness mediation effect on the relation between stressful life events and college students' subjective well-being, if there is a mediation effect, to further explore the "how".

\section{Methods}

\subsection{The Participants}

Using cluster random sampling, the selection of three universities in xi 'an region of shaanxi province 207 college students $(M=21.41, S D=21.41)$ as the object of investigation. Of shaanxi normal university, 66, 60 people in Xi'an university of technology, xi 'an college of science and engineering 81 people; 65 Boys and 142 girls.

\subsection{Tools}

\subsubsection{Stressful Life Events Scale}

Consulting the research of Liu Xianchen, Liu Lianqi et al., the stressful life events scale, measure the college students' interpersonal relationships, learning stress, and loss of property punishment, relatives and friends, health, and adapt to problems and other aspects of life events. Using scoring at six, from "no" to "happened and there are very severely impact", 1 to 6 points, respectively. To calculate an average of 27 project, the higher the score the more stressful life events happened, the greater the impact. The measurement of stressful life events of cronbach alpha coefficient is 0.85 , a good internal consistency reliability.

\subsubsection{Operational Effectiveness Questionnaire}

This research adopted the professor JiehuiTong, of the written operational effectiveness questionnaire [7], the questionnaire contains 17 questions, divided into three dimensions: the competence, degree of cognitive level and confidence, is used to assess individual in the past to deal with the problem of experience and ability to cope with life's events in the future. Using likert scoring at 4 points, from "completely does not conform to the" to 
"completely in line with" plan 1 to 4 points, respectively. Calculate all the average of all project, the higher the score said the individual's ability to deal with the problem. The scale of the cronbach alpha coefficient is 0.86 , $1 / 2$ reliability is 0.79 , shows that the questionnaire has good reliability.

\subsubsection{Subjective Well-Being Questionnaire}

This research adopted General Well-being Questionnaire developed by American psychologist Fazio, 1977 revision, used to measure the subjective well-being of people, a total of 33 items, each question has 5 to 7 options, is divided into six scales, life satisfaction and interestion, fear of health, energy, sad or happy mood, control of the emotions and behavior, and relaxation and tension. To calculate the average, scores for all project, the higher the said subjective well-being is higher. The scale in 1996 by the psychologist Jianhua Duan was revised in China, the revised scale of a single project scores and total score between $0.47-0.79$, retest internal consistency coefficient is 0.84 .

\subsubsection{Statistical Analysis}

Using SPSS 16.0 to correlation analysis, the use of AMOS 17.0 path graph is established.

\subsection{Procedure}

After subjects' permission and promising all the content will be confidential, questionnaires were measured. Make sure participators understand that there is not right and wrong, the questionnaire results to do scientific research only asked participants to request according to the instructions carefully, independent. All participants completed questionnaires about 15 minutes, all the questionnaires get back on the spot.

\section{Results}

Scores of three scale K-S single sample S normal distribution test, results show that the scale of the three scores in accordance with normal distribution $(p>0.05)$.

\subsection{Demographic Differences}

Demographic data of variance analysis and independent samples $\mathrm{T}$ test, the results show that college students' gender, age, ethnic, professional in stressful life events, operational effectiveness and subjective well-being there is no significant difference ( $p>0.05$ ), if only in terms of operational effectiveness and subjective well-being and no significant difference ( $p>0.05$ ), however, if ony-child significant differences on the stressful life events $(\mathrm{T}=$ 2.646, $p<0.05$ ), The results are shown in Table 1

As we can be seen from Table 1 , the only significant differences on the stressful life events $(p<0.05)$, suggesting the not only-child is facing more stressful life events in the lives of than only children.

\subsection{Correlation Matrix as Shown in Table 2}

Correlation analysis showed that the college students' subjective well-being and stressful life events were related to each dimension is: with interpersonal relationships, learning pressure, or punishment, health and adaptation and property loss of loved ones show significant negative correlation $(p<0.01)$, related to the operational effectiveness of each dimension are negatively related to the competency has significantly $(p<0.01)$, and cognitive level and degree of confidence has significantly negative correlation $(p<0.01)$.

\subsection{The Mediation Effect of Operational Effectiveness}

Use Amos17.0, operational effectiveness as intermediary variables, analysis of the operational effectiveness in Table 1. T test results on the stressful life events of if only-child.

\begin{tabular}{ccccc}
\hline If only-child & M & SD & $F$ & $p$ \\
\hline 1 & 51.35 & 16.41 & 9.769 & 0.002 \\
\hline
\end{tabular}

Note: 1: only-child, 2: not only children. 
Table 2. The variable correlation matrix.

\begin{tabular}{ccccc}
\hline & Cognitive level & Degree of confidence & competency & Subjective well-being \\
\hline Interpersonal relationships & $0.74^{* *}$ & $0.36^{* *}$ & -0.01 & $-0.26^{* *}$ \\
Academic pressure & $0.76^{* *}$ & $0.25^{* *}$ & 0.01 & $-0.16^{*}$ \\
punishment & $0.83^{* *}$ & $0.18^{*}$ & 0.004 & $-0.18^{* *}$ \\
loss & $0.87^{* *}$ & $0.15^{*}$ & 0.01 & 0.01 \\
adaption & $0.78^{* *}$ & $0.22^{* *}$ & 0.02 & $-0.21^{* *}$ \\
\hline
\end{tabular}

Note: ${ }^{*} p<0.05,{ }^{* *} p<0.01,{ }^{* * *} p<0.001$, the same below.

the stressful life events affect college students' subjective well-being of intermediary role, to build the path diagram as shown in Figure 1.

Operational effectiveness as intermediary variables as shown in the path diagram is established. The fitting index $\chi^{2}=0.313, \mathrm{df}=3, \mathrm{P}=0.958, \chi^{2} / \mathrm{df}=0.104, \mathrm{GFI}=0.999$, CFI $=1.000$, RMSEA $=0.000$. By the graph, we can see that stressful life events impact on the subjective well-being of college students there are four paths: Stressful life events have a direct negative effect on subjective well-being; Stressful life events affect subjective well-being through confidence; Stressful life events affect subjective well-being through cognitive level and degree of confidence; Stressful life events affect subjective well-being through confidence and competence.

\section{Discussion}

\subsection{Differences in Demographic Data Inspection}

On demographic data in ANOVA and independent sample $\mathrm{T}$ test and found that college students' gender, age, ethnic, professional in stressful life events, operational effectiveness and subjective well-being were there is no significant difference $(p>0.05)$, if only child in terms of operational effectiveness and subjective well-being and no significant difference $(p>0.05)$. However, if only-child has significant differences on the stressful life events ( $T=2.646, p<0.05$ ), showing that compared with the only-child, not only children exposed to more the stressful life events in the life, this is a potential threat on their subjective well-being.

Because of irreversibility is the only and family environment, if we want to improve college students' not only children subjective well-being, on the one hand, to control the frequency of the stressful life events to their daily life, more important is to improve their operational effectiveness, confidence, to be exact, to make them better able to face the stressful life events, improve the subjective well-being.

\subsection{The Stressful Life Events and Subjective Well-Being}

College students face stressful life events from all aspects of life, society, schools and families can be the source of the stressful life events. College students are still not fully into the society, facing the stressful life events, their subjective well-being will be significantly affected. This study from the six dimensions of stressful life events to collect data, analyze the relationship between the stressful life events and college students' subjective well-being. Results show that the interpersonal relationship, learning pressure, or punishment, health and adaptation and property loss of loved ones are showed significant negative correlation and college students subjective well-being, that is to say, stressful life events negative predict college students' subjective well-being $(r=0.227$, $p<0.05$ ), The impact of stressful life events, the more, the greater the lower the subjective well-being of college students. Stressful life events is direct influence on college students' subjective well-being, stressful life events, will reduce college students' subjective well-being. Therefore, if we want to improve the subjective well-being of college students, should start from controling stressful life events: create good interpersonal environment, reduce the pressure of learning, to reduce the punishment situation, for health and adapt to problems and or property loss psychological intervention, to help it as soon as possible out of the shadow of stressful life events, improve the subjective well-being.

\subsection{The Mediation Role of Operational Effectiveness}

This study used path graph to analyze operational effectiveness of the mediation effect, the results show that the 


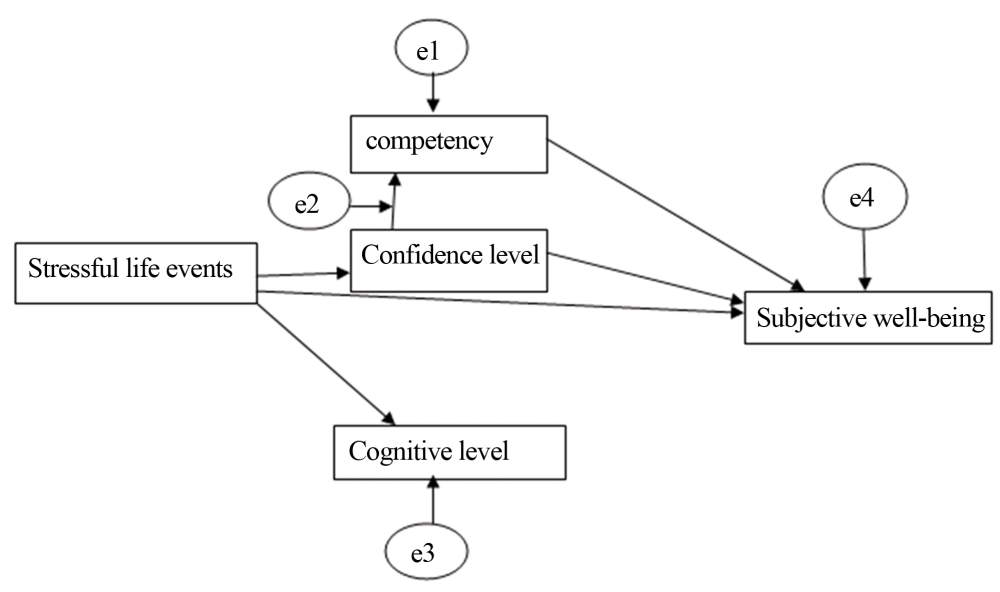

Figure 1. The mediating role of operational effectiveness in the stressful life events the college students' subjective well-being path graph.

operational effectiveness in the stressful life events and played a partial mediation role between college students' subjective well-being. Operational effectiveness in three dimensions: the competence, self-confidence and cognitive level, path graph analysis shows that there are three paths about the mediation effect on how stressful life events impact on college students' subjective well-being: stressful life events affect subjective well-being through confidence; Stressful life events affect subjective well-being through cognitive level and confidence; Stressful life events affect subjective well-being through confidence and competence.

The three mediation effect paths of operational effectiveness shows that confidence plays a crucial role. In fact, we can see from Figure 1, operational effectiveness, the other two dimensions both competence and cognitive level, the influence on subjective well-being only generate through the confidence. Stressful life events through individual cognitive level, the impact of individual level of confidence, thus influence the individual subjective well-being; Stressful life events through the individual level of confidence affect the individual competency, which affect the individual subjective well-being. The higher the degree of confidence, the ability to deal with stressful life events is higher, the higher the college students' subjective well-being. Confidence in operational effectiveness is very important, so how to improve college students' level of confidence is clear: improving college students' confidence can promote their ability to cope with stressful life events, and once the stressful life events occur, they can deal with it well, subjective well-being remain intact. Schools shall organize middle difficulty activities, to encourage college students to participate in. From a personal point of view, students should also exercise themselves, increase the degree of confidence, in order to better cope with stressful life events, and improve the subjective well-being.

But there is limition about this research. The data all comes from questionnaires, it is sufficient to analyse the relation of the three variables, but not enough if we want these results to do some good in the real world. In the future research, maybe some field experiments are required to find out, from behavior perspective, that if we do promote operational effectiveness, college students will have higher subjective well-being.

\section{Conclusions}

Through questionnaire, this study collected the university students who cope with the stressful life events, efficiency and subjective well-being aspects of the data, by using SPSS16.0 and Amos17.0. We analyse the data and results show that:

a) Compared with the one-child, not only children face more stressful life events;

b) Correlation analysis shows that stressful life events of each dimension negatively predict college students' subjective well-being and operational effectiveness positively predicts college students' subjective well-being;

c) Operational effectiveness is the mediator in stressful life event affects college students' subjective well-being; there were four paths of machine processed: stressful life events have a direct negative effect on college students' subjective well-being; stressful life events affect college students' subjective well-being through confidence; stressful life events affect college students' subjective well-being through cognitive level and degree of confidence; stressful life events affect college students' subjective well-being through confidence and competence. 


\section{References}

[1] Xia, F. and Ye, B.J. (2014) Stressful Life Events Affect Adolescent Tobacco Use: Basic Psychological Needs and to Respond to the Chain of Mediation Effect. Psychological Science, 5, 1385-1391.

[2] Yang, Q. and Ye, B.J. (2014) Stressful Life Events Affect Worker-Student Drug Use: Family Function and Understanding the Role of Social Support. Journal of Psychological Science, 5, 111-116.

[3] Li, H. and Zhang, W. (2011) Teenagers Stressful Life Events, the Relationship between Operational Effectiveness and Suicidal Ideation. Journal of Special Education in China, 3.

[4] Ye, B.J., Hu, X.Y., Yang, Q. and Hu, Z.J. (2014) Understanding Social Support, Operational Effectiveness and Stressful Life Events Affect Adolescent Academic Achievement Mechanism. Journal of Psychological Science, 11, 342-348.

[5] Wang, J.P., Li, D.P. and Zhang, W. (2010) Families Are Financially Difficult Relationship with the Adolescent Social Adaptation: The Compensation for Operational Effectiveness, Mediation and Regulating Effect. Journal of Beijing Normal University (Social Science Edition), 4.

[6] Wen, Z.L. and Ye, B.J. (2014) Mediation Effect Analysis: Methods and Model Development. Progress in Psychological Science, 12, 731-745.

[7] Tong, J.H. (2005) Operational Effectiveness: Questionnaire Compiled and the Construction of Theoretical Model. Journal of Psychology, 5, 413-419.

\section{Submit or recommend next manuscript to SCIRP and we will provide best service for you:}

Accepting pre-submission inquiries through Email, Facebook, Linkedin, Twitter, etc

A wide selection of journals (inclusive of 9 subjects, more than 200 journals)

Providing a 24-hour high-quality service

User-friendly online submission system

Fair and swift peer-review system

Efficient typesetting and proofreading procedure

Display of the result of downloads and visits, as well as the number of cited articles

Maximum dissemination of your research work

Submit your manuscript at: http://papersubmission.scirp.org/ 